\title{
Education Level Among Patients with Major Limb Amputation
}

\author{
Ivan Chernev ${ }^{1,2}$, Alexandra Chernev ${ }^{2}$ \\ 1. Orthopedics, Medical University of South Carolina (MUSC) Health Florence Medical Center, Florence, USA 2. \\ Physical Medicine and Rehabilitation, Palmetto Amputee Network, Florence, USA
}

Corresponding author: Ivan Chernev, ivantchernev@yahoo.com

\section{Abstract \\ Introduction}

Despite all the advances in medicine and attempts to delay and prevent amputations, the number of amputations remains high. The state of South Carolina has one of the highest rates of major limb amputation in the country, with Florence and neighboring counties particularly affected. Education level has been associated with an increased number of amputations and worse outcomes post-amputation. The aim of this study was to investigate the education level among patients with major upper and lower limb amputation within the Florence and neighboring counties, which is a part of the Pee Dee region of the state of South Carolina.

\section{Materials and methods}

This is a retrospective chart review study conducted at the outpatient hospital-based Physical Medicine and Rehabilitation clinic. All consecutive amputee patients visiting our outpatient amputee clinic from January 2018 to January 2019 and who met the study inclusion criteria were included in the study. The main outcome measure was the education level.

\section{Results}

Of the sample, $26 \%$ had below high school education, $33.8 \%$ had high school education, $14.2 \%$ had some college education, $19.7 \%$ had a college education, and $6.3 \%$ had an advanced college degree.

\section{Conclusions}

Patients with major limb amputation have a lower education level compared to the general population. Lower education level as a part of the broader and more complex socioeconomic status may be a possible barrier in the process of post-amputation rehabilitation and long-term care of patients with major limb amputation.

Received 04/02/2020 Review began 04/08/2020 Review ended 04/08/2020 Published 04/14/2020

\section{() Copyright 2020}

Chernev et al. This is an open access article distributed under the terms of the Creative Commons Attribution License CC-BY 4.0., which permits unrestricted use, distribution, and reproduction in any medium, provided the original author and source are credited.

\begin{abstract}
Categories: Physical Medicine \& Rehabilitation, Orthopedics, Public Health
Keywords: education, major limb amputation, limb loss, socioeconomic, rehabilitation
\end{abstract}

\section{Introduction}

Limb loss is a major and a life-changing event leading to permanent disability, significant functional impairment, and decreased quality of life [1,2]. Each year, an estimated 185,000 people undergo amputation in the United States, with the overall number of amputations being performed increasing [3,4]. Furthermore, nearly two million individuals have some level of limb amputation, with most amputations affecting the lower limb [3,5]. In addition, the state of South Carolina has one of the highest rates of major limb amputation in the country, with Florence and neighboring counties particularly affected [6,7]. Goodney et al. reported an amputation rate of more than 23 per 10,000 Medicare patients with the peripheral arterial disease (PAD) in Florence, South Carolina [6]. Certain factors, such as age, gender, race, co-existing diseases, smoking, and socioeconomic status, among others, have been associated with higher rates of amputation [6,8-12]. For example, Ciocan et al. identified age as a risk factor for amputation [8]. Arya et al. found the race to be independently predictive of major limb amputation in patients with PAD [11]. Ferguson et al., Arya et al., Stevens et al., and Goodney et al. all showed a positive association between low socioeconomic status and rates of major limb amputation [6,10-12].

Despite all the advances in medicine and attempts to delay and prevent amputations, the number of amputations remains high. With the increasing prevalence of amputations, it is equally important to manage patients' post-amputation. Achieving independence and regaining the ability to walk can have a significant impact on the amputee's quality of life and reintegration in the community. Furthermore, maintaining mobility, functional level, and preventing complications from prosthetic use is a critical part of the long-term management of patients with major limb amputation. Variables such as age, etiology of amputation, level of amputation, bilateral amputation, body mass index, phantom and residual limb pain, co-morbidities, marital status, psychosocial support, and access to medical care and rehabilitation services can affect adjustment to amputation, post-amputation and prosthetic rehabilitation, and long-term 
prosthetic use [4,5,13-15]. Education level has also been previously cited to affect different outcome measures and mortality after amputation. Nunes et al. found that patients with low education level showed lower rates of adaptation to prosthesis [14]. In a review of the literature, Darter et al. found that education level was associated with return to work rates [5]. Amputees with higher education level had more job opportunities and more flexibility in their work schedules [5]. Corey et al. showed increased five-year mortality for patients who did not complete high school education compared to those who completed high school education [16]. They also found that patients who completed high school education were more likely to ambulate with a prosthesis following amputation [16]. As education may affect different aspects of postamputation rehabilitation, understanding regional population-based education level differences among patients with major limb amputation will allow proper strategy and utilization of resources in the management of this less fortunate population. Therefore, the aim of this study was to investigate the education level among patients with major upper and lower limb amputation within the Florence and neighboring counties, which is a part of the Pee Dee region of South Carolina.

\section{Materials And Methods}

This was a retrospective chart review study. The study was approved by the institutional review board. Data were collected from the electronic medical records of all patients with major upper and lower limb amputation who visited our single-site hospital-based outpatient Physical Medicine and Rehabilitation clinic from January 2018 to January 2019 and who met the study inclusion criteria. This clinic serves the largest volume of patients in the area who require post-amputation rehabilitation and prosthetic management.

The inclusion criteria were that the subjects should be patients who had undergone unilateral, bilateral, or multiple upper and lower limb amputation performed at or above the wrist for the upper limb and at or above the ankle for the lower limb and be 20 years or older at the first visit during the study period. Data were collected only from the first visit during the study period in case the patient had a subsequent follow-up visit. In addition, amputations from all etiologies (trauma, disease-related, neoplasm, and congenital) were included. The exclusion criteria were patients with major amputation younger than 20 years old. Other than education level, data obtained from the electronic medical record included age, gender, race, etiology of amputation, laterality of amputation, level of amputation, and $\mathrm{K}$ level. All data were gathered on a standardized form. The education level was divided into five separate categories: below high school, high school, some college, college, and an advanced college degree. Below high school was designated to subjects who attended any level of elementary, middle, or high school but did not graduate. High school was designated to subjects who graduated high school or equivalent. Some college was designated to subjects who attended college but did not graduate from the program they had enrolled in. College was designated to subjects who completed the program they enrolled in but did not receive bachelor, master, or PhD degree. Advanced college degree was categorized as any subject who graduated with bachelor, master, and $\mathrm{PhD}$ degree.

Descriptive statistics were utilized to examine the demographic and clinical data. All variables were calculated as a percentage from the sample. Age was also presented as range and average.

\section{Results}

During the one-year study period, 127 subjects who met the study inclusion criteria were included in the study. Descriptive statistics of the demographic and clinical variables are presented in Table 1 . 


\section{Cureus}

Study Variables

Age

$<40$

41-50

$51-60$

$>60$

Gender

Male

Female

Race

African-American

Caucasian

Etiology of Amputation

Disease-related

Trauma

Neoplasm

Congenital

Laterality

Unilateral

BL/MLA

Level of Amputation

WD

TH

AD

BKA

KD

AKA

HD

BL/MLA

Functional Level

K-0

K-1

K-2

K-3

K-4

N/A n (\%)

\author{
20 (15.75\%) \\ $24(18.90 \%)$ \\ $32(25.20 \%)$ \\ $51(40.16 \%)$
}

$84(66.1 \%)$

43 (33.9\%)

77 (60.6\%)

50 (39.4\%)

95 (74.8\%)

$28(22 \%)$

2 (1.6\%)

$2(1.6 \%)$

$103(81.1 \%)$

24 (18.9\%)

$1(0.8 \%)$

$1(0.8 \%)$

$1(0.8 \%)$

66 (51.9\%)

$2(1.6 \%)$

$31(24.4 \%)$

$1(0.8 \%)$

24 (18.9\%)

$3(2.4 \%)$

$25(19.7 \%)$

$37(29.1 \%)$

$60(47.2 \%)$

$0(0 \%)$

$2(1.6 \%)$

TABLE 1: Background demographic and clinical characteristics of the study population

BL, bilateral; MLA, multiple limb amputation; WD, wrist disarticulation; TH, transhumeral amputation; AD, ankle disarticulation or Syme's amputation; BKA, below the knee amputation; KD, knee disarticulation; AKA, above the knee amputation; HD, hip disarticulation 
The average age of the subjects in this study was 55.9 years (range 21-91). Of these, 51 (40.16\%) were older than 60 years, followed by 32 (25.20\%) 51-60 years old, 24 (18.90\%) 41-50 years old, and 20 (15.75\%) under 40 years old. Within this sample, 84 (66.1\%) were men and 43 (33.9\%) were women. The majority of the sample, 77 (60.6\%) were African-American with the rest of the sample 50 (39.4\%) Caucasian. Most of the subjects, 95 (74.8\%) had amputation secondary to a disease (PAD, non-healing diabetic ulcer, infection, etc.) followed by 28 (22\%) trauma, two (1.6\%) congenital malformation, and two (1.6\%) neoplasm. Most of the subjects, 103 (81.1\%) had unilateral amputation with the rest of the $24(18.9 \%)$ bilateral or multiple limb amputation. Level of amputation was distributed as 66 (51.9\%) below the knee, 31 (24.4\%) above the knee, two (1.6\%) knee disarticulation, one ( $0.8 \%$ ) hip disarticulation, one ( $0.8 \%$ ) wrist disarticulation, one $(0.8 \%)$ transhumeral, one ( $0.8 \%$ ) ankle disarticulation (Syme's amputation), and 24 (18.9\%) bilateral/multiple limb amputation. Functional level was distributed as 60 (47.2\%) K-3, 37 (29.1\%) K-2, 25 (19.7\%) K-1, three (2.4\%) K-0, two (1.6\%) N/A, and zero (0\%) K-4. Finally, the majority of the subjects in this study, 43 (33.8\%) had high school education, followed by 33 (26\%) with below high school education, 25 (19.7\%) with a college education, 18 (14.2\%) with some college education, and eight (6.3\%) with advanced college degree education (Table 2).

\begin{tabular}{|l|l|}
\hline Education Level & $\mathrm{n}(\%)$ \\
\hline Below high school & $33(26 \%)$ \\
\hline High school & $43(33.8 \%)$ \\
Some college & $18(14.2 \%)$ \\
College & $25(19.7 \%)$ \\
Advanced college degree & $8(6.3 \%)$ \\
\hline
\end{tabular}

\section{TABLE 2: Distribution of education level among patients with major limb amputation}

\section{Discussion}

The present study is the first to collect education level data on patients with major limb amputation in parts of the Pee Dee region of South Carolina. Previous studies have reported education level as part of their demographic data collection. Sinha et al. found that $71 \%$ of amputees had high school academic training, $9 \%$ had a university education, and $18 \%$ had no schooling [2]. Nunes et al. found that $65 \%$ of amputees had a low level of education (subjects had not completed primary education) and $35 \%$ had a high level of education [14]. Raichle et al. reported that $5.5 \%$ of their lower limb amputee subjects had 9th grade or less education, $6.5 \%$ had 10 th to 11 th grade education, $19.1 \%$ had high school education, $10.2 \%$ had vocational/technical school education, $29.1 \%$ had some college education, $17.8 \%$ were college graduate, and $11.6 \%$ had graduate school education [4]. Corey et al. showed that 56.3\% completed high school and 43.7\% did not complete high school [16]. Lastly, Ephraim et al. found that $6.2 \%$ had less than high school education, $26.6 \%$ graduated high school, and $67.2 \%$ had greater than high school education [1]. However, due to the methodological differences in the education level data collection, it is difficult to completely compare the available studies. Nonetheless, many of the previously published studies have associated lower education level not only with an increased incidence of amputation, but also with worse outcomes after amputation.

The results from our study demonstrated that a little over one-fourth of the sample (26\%) had below high school education. This is significantly higher compared to the overall general population in the state of South Carolina (12.9\%). It is also higher compared to the general population of Florence county (15.4\%), Darlington county (17.9\%), Marion county (19.2\%), Marlboro county (24.1\%), and Dillon county (25.1\%) [17]. Furthermore, only $6.3 \%$ of our sample had advanced college degree which is lower compared to the state of South Carolina (27.4\%), Florence county (23.1\%), Darlington county (17.2\%), Marion county (14.4\%), Marlboro county (9.4\%), and Dillon county (11.1\%) [17].

Association between health and education has been established and numerous mechanisms through which education influences health has been suggested [18]. The most prominent mediating mechanisms can be grouped into four categories: economic, health-behavioral, social-psychological, and access to health care. Education may determine and affect individuals' knowledge, reasoning, healthier lifestyles, income, successful long-term marriage, social support, and access to better healthcare, all of which protect or enhance health. Less-educated adults reported worse general health, more chronic conditions, and more functional limitations and disability [18]. Similarly, our study showed lower education level of patients with major limb amputation compared to the general population, which may suggest that barriers such as the ability to understand basic health information, false health beliefs, disease self-management and compliance with treatment, and limited financial recourses may be an issue when dealing with patients with major limb amputation in our region. Furthermore, lower education level has been found to be a predictive factor for higher no-show rates and adherence to treatment $[19,20]$. Although not the aim of this study, we have also noticed a high no-show rate among amputee patients in our clinic. All of that may result in delayed medical care, rehabilitation, prosthetic fitting, and gait training. Delayed care may also increase the 
chance of developing complications such as joint contractures, muscle weakness, deconditioning, and residual limb ulcerations. For example, time from amputation to gait retraining has been shown to be predictive of prosthetic non-use with increased time inversely related to the likelihood of ambulation with a prosthesis [15,21]. In addition, high no-show rates may affect the cost of care and resource planning [22].

Our study also has some limitations. The study was limited by the nature of a single-clinic retrospective chart review. However, a standardized template for routine collection of amputee pertinent information has been implemented in our amputee clinic prior to this study, which has captured all of the data used in this study and has eliminated the problem of missing data. Only outpatient amputee subjects were included. This may have affected our overall education level distribution. However, these patients are the ones most likely to survive longer, be ambulatory, and require prosthetic care. We also did not investigate the education level distribution by county. This may have possibly given us better comparison and understanding by county. However, we would have needed a larger sample from each individual county, which may be difficult to obtain secondary to the population size and prevalence of patients with major limb amputation in each individual county.

\section{Conclusions}

In conclusion, patients with major limb amputation in Florence and neighboring counties have a lower education level compared to the general population in the region and the state of South Carolina. Education level as a part of the broader and more complex socioeconomic status may be a possible barrier in the process of post-amputation rehabilitation and long-term care of patients with major limb amputation. More aggressive approaches such as closer follow-ups, patient education and improving health literacy, confirmation that patients understand treatment recommendations, and more accessible transportation are some of the steps which may possibly improve the outcomes and the wellbeing of this population.

\section{Additional Information \\ Disclosures}

Human subjects: Consent was obtained by all participants in this study. Hospital institutional review board issued approval NA. This retrospective chart review study was not sponsored by the institution but rather conducted at the institution. The lead author/investigator, who is also employed by the institution, had formal meeting with the hospital institutional review board to discuss the nature of the study and complying with the rules and regulations. Permission was granted by the IRB during that meeting but no approval number was issued. At that time, our institution under the Carolinas Hospital System management did not issue IRB approval numbers. Subsequently, our hospital was sold to the Medical University of South Carolina and for future research IRB numbers will be issued. I have copy of the IRB approval letter and can e-mail it to the journal if needed. Animal subjects: All authors have confirmed that this study did not involve animal subjects or tissue. Conflicts of interest: In compliance with the ICMJE uniform disclosure form, all authors declare the following: Payment/services info: All authors have declared that no financial support was received from any organization for the submitted work. Financial relationships: All authors have declared that they have no financial relationships at present or within the previous three years with any organizations that might have an interest in the submitted work. Other relationships: All authors have declared that there are no other relationships or activities that could appear to have influenced the submitted work.

\section{Acknowledgements}

We would like to thank Petia Ignatova for clerical support during the preparation of this manuscript.

\section{References}

1. Ephraim PL, MacKenzie EJ, Wegener ST, Dillingham TR, Pezzin LE: Environmental barriers experienced by amputees: the Craig Hospital Inventory of Environmental Factors-Short Form. Arch Phys Med Rehabil. 2006, 87:328-333. 10.1016/j.apmr.2005.11.010

2. Sinha R, van den Heuvel WJ, Arokiasamy P: Factors affecting quality of life in lower limb amputees . Prosthet Orthot Int. 2011, 35:90-96. 10.1177/0309364610397087

3. Ziegler-Graham K, MacKenzie EJ, Ephraim PL, Travison TG, Brookmeyer R: Estimating the prevalence of limb loss in the United States: 2005 to 2050. Arch Phys Med Rehabil. 2008, 89:422-429. 10.1016/j.apmr.2007.11.005

4. Raichle KA, Hanley MA, Molton I, et al.: Prosthesis use in persons with lower- and upper-limb amputation . J Rehabil Res Dev. 2008, 45:961-972. 10.1682/JRRD.2007.09.0151

5. Darter BJ, Hawley CE, Armstrong AJ, Avellone L, Wehman P: Factors influencing functional outcomes and return-to-work after amputation: a review of the literature. J Occup Rehabil. 2018, 28:656-665. 10.1007/s10926-018-9757-y

6. Goodney PP, Holman K, Henke PK, et al.: Regional intensity of vascular care and lower extremity amputation rates. J Vasc Surg. 2013, 57:1471-1480. 10.1016/j.jvs.2012.11.068

7. Wrobel JS, Mayfield JA, Reiber GE: Geographic variation of lower-extremity major amputation in individuals with and without diabetes in the Medicare population. Diabetes Care. 2001, 24:860-864. 10.2337/diacare.24.5.860

8. Ciocan RA, Bolboacă SD, Rădulescu Ş, Stancu B, Ciocan A, Gherman CD: Demographic and comorbidity pattern of patients with critical limb ischemia. Folia Med. 2017, 59:14-22. 10.1515/folmed-2017-0014

9. Girijala RL, Bush RL: Review of socioeconomic disparities in lower extremity amputations: a continuing 
healthcare problem in the United States. Cureus. 2018, 10:e3418. 10.7759/cureus.3418

10. Ferguson HJ, Nightingale P, Pathak R, Jayatunga AP: The influence of socio-economic deprivation on rates of major lower limb amputation secondary to peripheral arterial disease. Eur J Vasc Endovasc Surg. 2010, 40:76-80. 10.1016/j.ejvs.2010.03.008

11. Arya S, Binney Z, Khakharia A, et al.: Race and socioeconomic status independently affect risk of major amputation in peripheral artery disease. J Am Heart Assoc. 2018, 7:e007425. 10.1161/JAHA.117.007425

12. Stevens CD, Schriger DL, Raffetto B, Davis AC, Zingmond D, Roby DH: Geographic clustering of diabetic lower-extremity amputations in low-income regions of California. Health Aff (Millwood). 2014, 33:13831390. 10.1377/hlthaff.2014.0148

13. Chopra A, Azarbal AF, Jung E, et al.: Ambulation and functional outcome after major lower extremity amputation. J Vasc Surg. 2018, 67:1521-1529. 10.1016/j.jvs.2017.10.051

14. Nunes MA, Campos-Neto I, Ferraz LC, Lima CA, Rocha TO, Rocha TF: Adaptation to prostheses among patients with major lower-limb amputations and its association with sociodemographic and clinical data. Sao Paulo Med J. 2014, 132:80-84. 10.1590/1516-3180.2014.1322572

15. Roffman CE, Buchanan J, Allison GT: Predictors of non-use of prostheses by people with lower limb amputation after discharge from rehabilitation: development and validation of clinical prediction rules. J Physiother. 2014, 60:224-231. 10.1016/j.jphys.2014.09.003

16. Corey MR, St Julien J, Miller C, et al.: Patient education level affects functionality and long term mortality after major lower extremity amputation. Am J Surg. 2012, 204:626-630. 10.1016/j.amjsurg.2012.07.018

17. United States Census Bureau QuickFacts . (2019). Accessed: March 30, 2020: https://www.census.gov/quickfacts/fact/table/marlborocountysouthcarolina,marioncountysouthcarolina,dilloncountysouth

18. Zajacova A, Lawrence EM: The relationship between education and health: reducing disparities through a contextual approach. Annu Rev Public Health. 2018, 39:273-289. 10.1146/annurev-publhealth-031816044628

19. Wolff DL, Waldorff FB, von Plessen C, et al.: Rate and predictors for non-attendance of patients undergoing hospital outpatient treatment for chronic diseases: a register-based cohort study. BMC Health Serv Res. 2019, 19:386. 10.1186/s12913-019-4208-9

20. DiMatteo MR: Variations in patients' adherence to medical recommendations: a quantitative review of 50 years of research. Med Care. 2004, 42:200-209. 10.1097/01.mlr.0000114908.90348.f9

21. Kahle JT, Highsmith MJ, Schaepper H, Johannesson A, Orendurff MS, Kaufman K: Predicting walking ability following lower limb amputation: an updated systematic literature review. Technol Innov. 2016, 18:125-137. $10.21300 / 18.2-3.2016 .125$

22. Kheirkhah P, Feng Q, Travis LM, Tavakoli-Tabasi S, Sharafkhaneh A: Prevalence, predictors and economic consequences of no-shows. BMC Health Serv Res. 2016, 16:13. 10.1186/s12913-015-1243-Z 